\title{
Effects of Groundwater Exploitation on Embankment for High-speed Railway Lines
}

\author{
Luwei Huang, Hong Xiao*, Song Yang, Yugang Han
}

Beijing Key Laboratory of Track Engineering, Beijing Jiaotong University, 100044, Beijing, P. R. China

\begin{abstract}
Groundwater exploitation will cause significant subsidence to the ground, then influence the deformation of embankment for high-speed railway lines, which may threaten the safety of train operation. To study the law of embankment deformation aroused by groundwater exploitation near high-speed railway lines, a 3D fluid-solid coupling model is established based on infiltrating solidification theory and using finite element software ABAQUS, and embankment deformations caused by different pumping rates and pumping distance are analyzed. The results show that pumping rate and pumping distance are both of great influence on the deformations of embankment for high-speed railway lines. Therefore, in order to control the effects of groundwater exploitation on embankment, it should be forbidden to add new pumping well near the railway lines and groundwater exploitation should be strictly limited within the influence scope.
\end{abstract}

Keywords: Embankment subsidence, groundwater exploitation, high-speed railway, numerical simulation.

\section{INTRODUCTION}

There is a directly relevant relationship between ground subsidence and groundwater exploitation, and many areas of China have seen the increasingly prominent phenomenon of land subsidence due to over-exploitation of groundwater, which will lead to the increasing economic loss. At present, more than half of land subsidence in China is caused by excessive exploitation of groundwater, and the subsidence situation in more than 50 cities is very serious, and North China Plain which includes Beijing has become the largest groundwater funnel area in the world [1].

China has become the country that has both the longest operation and construction length of high-speed railway in the world. According to Mid-term and Long-term Railway Network Planning, more high-speed railway lines will be constructed. According to previous research, many highspeed railway lines have been constructed in severesubsidence areas. For example, many provinces which Beijing-Shanghai high-speed railway crosses through have seen large land subsidence, including east and south part of Beijing, Wuqing, Xiqing, Jinghai and Binhai of Tianjing, Cangzhou of Hebei Province, Dezhou of Shangdong Province [2, 3], Suzhou, Wuxi, Changzhou of Jiangsu Province $[4,5]$ and Shanghai $[6,7]$. The extent and history of land subsidence in these areas are not the same with each other, and the land subsidence in Tianjin and Suzhou, Wuxi, Changzhou of Jiangsu Province are the most serious.

High-speed railway has very strict requirements for embankment deformations. Code For Design Of High Speed Railway regulates that [8], when the train operating speed reaches $300 \mathrm{~km} / \mathrm{h}$, the post-construction subsidence value of embankment for ballast track shall be no more than $5 \mathrm{~cm}$, the post-construction subsidence value of embankment for transition section between abutment and tail shall be no more than $3 \mathrm{~cm}$ and subsidence rate shall be no more than 2 $\mathrm{cm} /$ year. The post-construction subsidence value of embankment for ballastless track shall meet the requirements for fastener adjustment and coordination of vertical curve of the line, and the value shall be no more than the allowed fastener adjustment amount $15 \mathrm{~mm}$. However, the coupling of land subsidence induced by excessive groundwater exploitation and post-construction subsidence of embankment will lead to excessive subsidence and uneven subsidence of upper structure, which will cause additional gradient of the line and has a strong impact on the safety of train operation. Therefore, it is necessary to control the embankment deformation.

\section{NUMERICAL MODELING}

\subsection{Determination of Influence Scope and Pumping Distance}

\subsubsection{Influence Scope of Pumping}

As for pumping of shallow groundwater, influence scope of pumping can be determined by pumping test. The influence scope is estimated by empirical formula in this paper [9]:

$$
R=3000 S \sqrt{K}
$$

where $\mathrm{S}$ is drawdown of groundwater in $\mathrm{m}, \mathrm{K}$ is permeability coefficient of aquifer in $\mathrm{m} / \mathrm{s}, \mathrm{R}$ is influence scope in $\mathrm{m}$.

\subsubsection{Pumping Rate}

According to the actual working conditions, a pumping well whose radius is $r$ is established in the model, and the 
groundwater level is supposed to be $3 \mathrm{~m}$ under the ground, the scope of extraction is the entire aquifer (from depth of 3 to $17 \mathrm{~m}$ ), therefore the velocity, $\mathrm{v}$, of inflow across the surface of the well can be calculated from [10]:

$$
v=\frac{Q}{2 \pi \cdot r \cdot n \cdot l}
$$

where $\mathrm{Q}$ is the pumping rate in $\mathrm{m}^{3} / \mathrm{d}, \mathrm{r}$ is the radius of the well in $\mathrm{m}, \mathrm{n}$ is porosity, 1 is the length of the intake screen in $\mathrm{m}$.

\subsection{Geometry Model}

The 3-D fluid-solid coupling model is established using ABAQUS finite element program. According to the influence scope calculated above, and considering the influence of boundary effect finite element model, the scale of the model should be larger than the influence scope. When the size of the model is $300 \times 300 \mathrm{~m}^{2}$, the boundary effect can be reduced to a very low degree. The relationship between embankment and pumping well is shown in Fig. (1). The width of the left side of the embankment is $50 \mathrm{~m}$, and width of the right side of the embankment is $250 \mathrm{~m}$, the distance from well to boundary is $50 \mathrm{~m}$ and longitudinal length of the railway line is $300 \mathrm{~m}$.
The depth of the strata is $28 \mathrm{~m}$, which includes 3 layers. Double-line ballastless track is adopted for the line. Width of the embankment surface is $13.6 \mathrm{~m}$, thickness of the embankment is $4.2 \mathrm{~m}$, and gradient of embankment slope is $1: 1.5$. Parameters of embankment and each stratum are shown in Table 1.

The C3D8P (8-node completely integral pore fluid) elements are adopted for the model, the head pressure of the boundary and the void ratio are supposed to be constant. The distribution function is used to simulate the hydrostatic pressure which is dependent on the elevation around the boundary, and other surfaces are prescribed as no flow boundaries. The established model is shown in Fig. (2).

\section{RESULTS AND DISCUSSION}

During groundwater extraction, the pumping rate of well and the distance between well and embankment are the main factors that influencing the deformations of the embankment. Therefore, the influencing law of pumping rate and pumping distance on embankment deformations are studied in the paper. Computational contours of the working condition of pumping distance at $200 \mathrm{~m}$, pumping rate at $1500 \mathrm{~m}^{3} / \mathrm{d}$ are shown in Figs. (3-7).

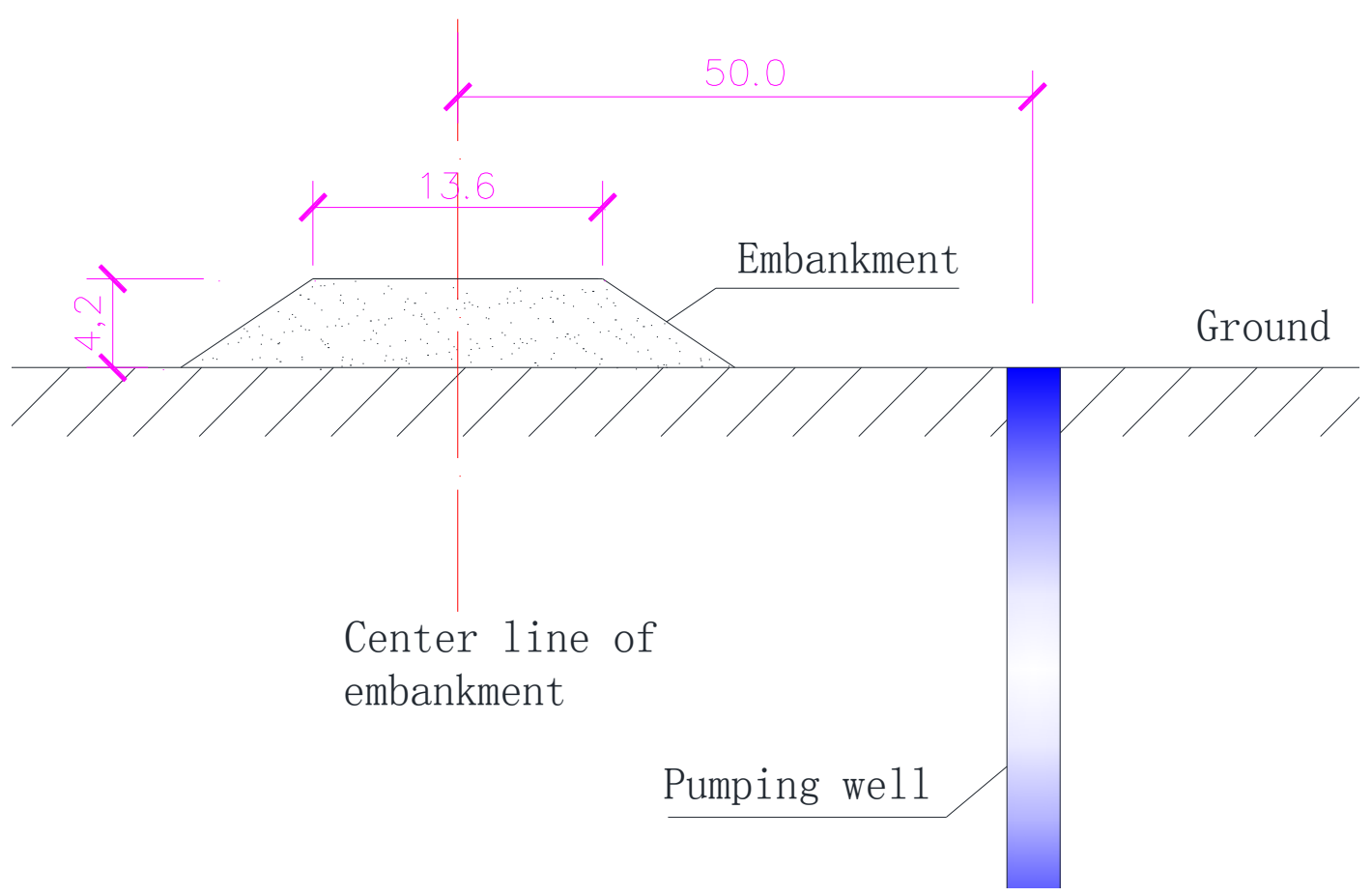

Fig. (1). Relationship between embankment and pumping well (unit:m).

Table 1. Parameters of embankment and each stratum in research area.

\begin{tabular}{|c|c|c|c|c|c|c|}
\hline & Thickness (m) & Density $\left(\mathrm{kg} / \mathbf{m}^{3}\right)$ & Void Ratio & Young Modulus (N/m $\left.\mathbf{m}^{2}\right)$ & Poisson's Ratio & Permeability Coefficient $(\mathrm{m} / \mathrm{s})$ \\
\hline Embankment & 4.2 & 2100 & 0.4 & $1.5 \mathrm{E} 8$ & 0.25 & $4.0 \mathrm{E}-6$ \\
\hline Backfill Soil & 3 & 2230 & 0.4 & $7.0 \mathrm{E} 6$ & 0.30 & $4.0 \mathrm{E}-7$ \\
\hline Sand & 14 & 1700 & 0.3 & $1.0 \mathrm{E} 9$ & 0.25 & $5.0 \mathrm{E}-5$ \\
\hline Clay & 11 & 1800 & 0.9 & $2.5 \mathrm{E} 7$ & 0.30 & $1.0 \mathrm{E}-9$ \\
\hline
\end{tabular}




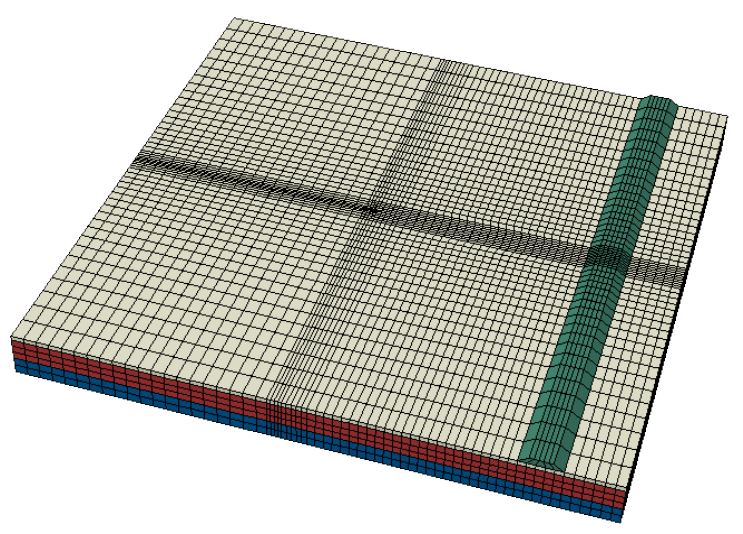

Fig. (2). Sketch of 3D finite element model.

As can be seen from Fig. (3), pore pressure near the pumping well is negative, and the nearer from the well, the larger the pore pressure. As can be seen from Figs. $(\mathbf{4}, \mathbf{5})$, subsidence of the soil near pumping well shows an obvious regularity, that is, the nearer from the well, the larger the land subsidence, which is a concentric circle, and forming a subsidence funnel. Pumping of groundwater near the line has a marked influence on embankment, and the subsidence of embankment soil shows as the longitudinal uneven subsidence, the subsidence of the center in longitudinal direction is larger than those of two sides. As can be seen from Figs. $(6,7)$, lateral deformation of the soil near the well roughly shows a symmetrical distribution, which indicates that the soil is moving towards the well, and this is relevant to the negative pore pressure.

\subsection{Influence of Different Pumping Rates on Embankment}

To study the influence of pumping rate on embankment deformations, under the condition of pumping distance at $200 \mathrm{~m}$, the working conditions with six different pumping rates $250 \mathrm{~m}^{3} / \mathrm{d}, 500 \mathrm{~m}^{3} / \mathrm{d}, 750 \mathrm{~m}^{3} / \mathrm{d}, 1000 \mathrm{~m}^{3} / \mathrm{d}, 1250 \mathrm{~m}^{3} / \mathrm{d}$ and $1500 \mathrm{~m}^{3} / \mathrm{d}$ are analyzed. The center of embankment surface is selected as the object of study, and the results are shown in Figs. $(\mathbf{8}, \mathbf{9})$.

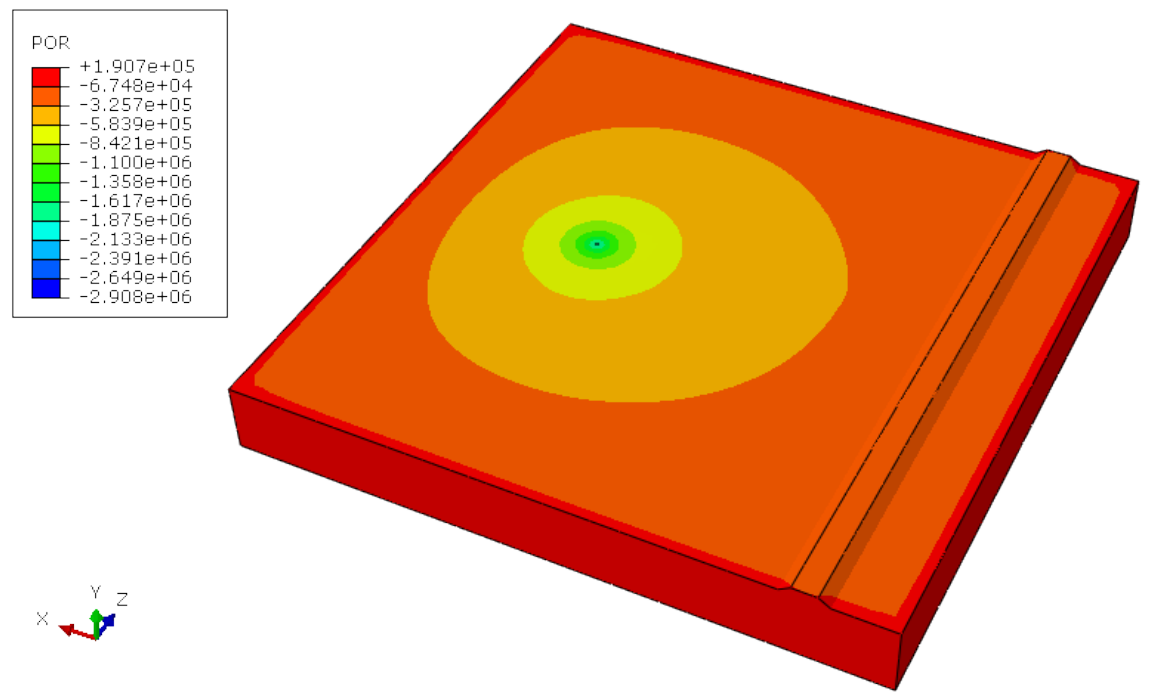

Fig. (3). Contours of pore pressure.

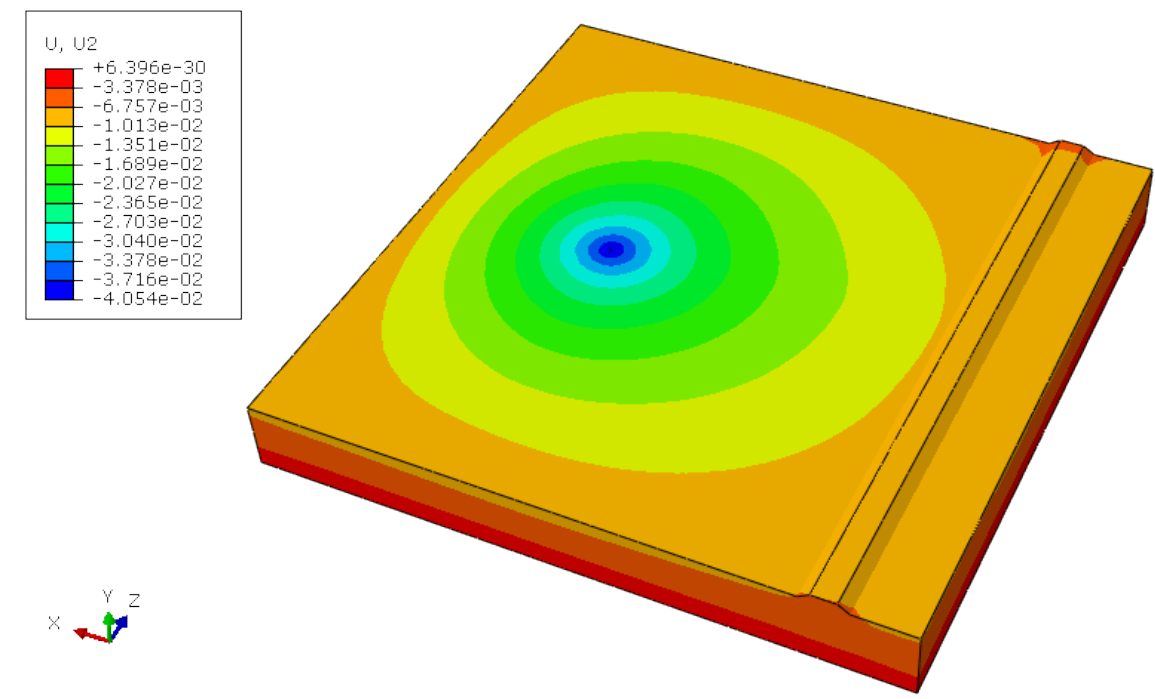

Fig. (4). Contours of vertical deformation. 

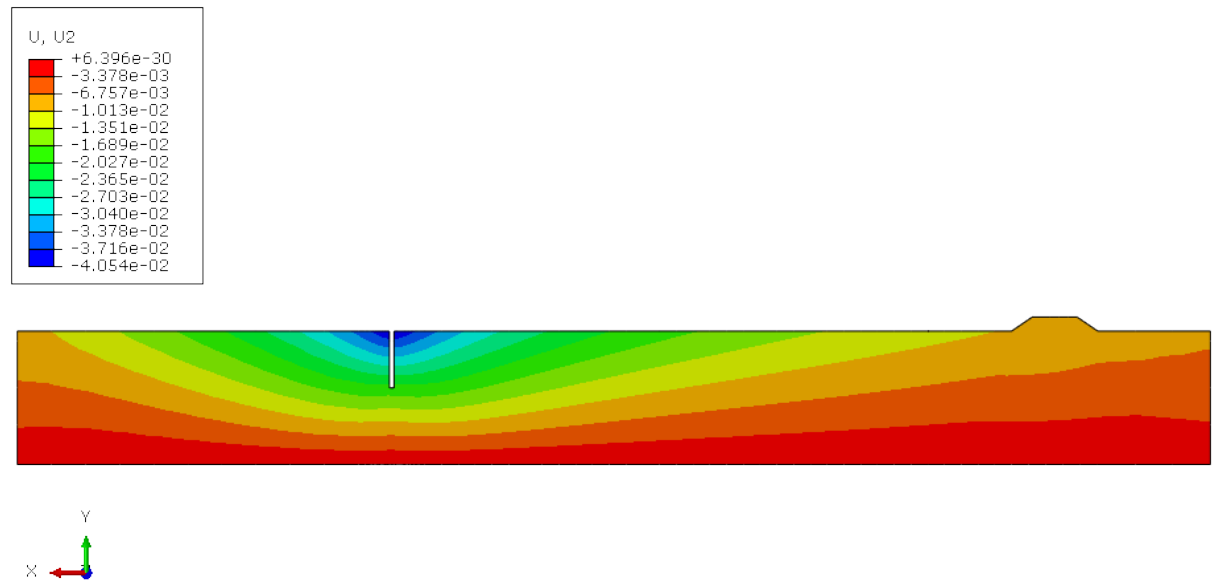

Fig. (5). Cross section of vertical deformation contours.

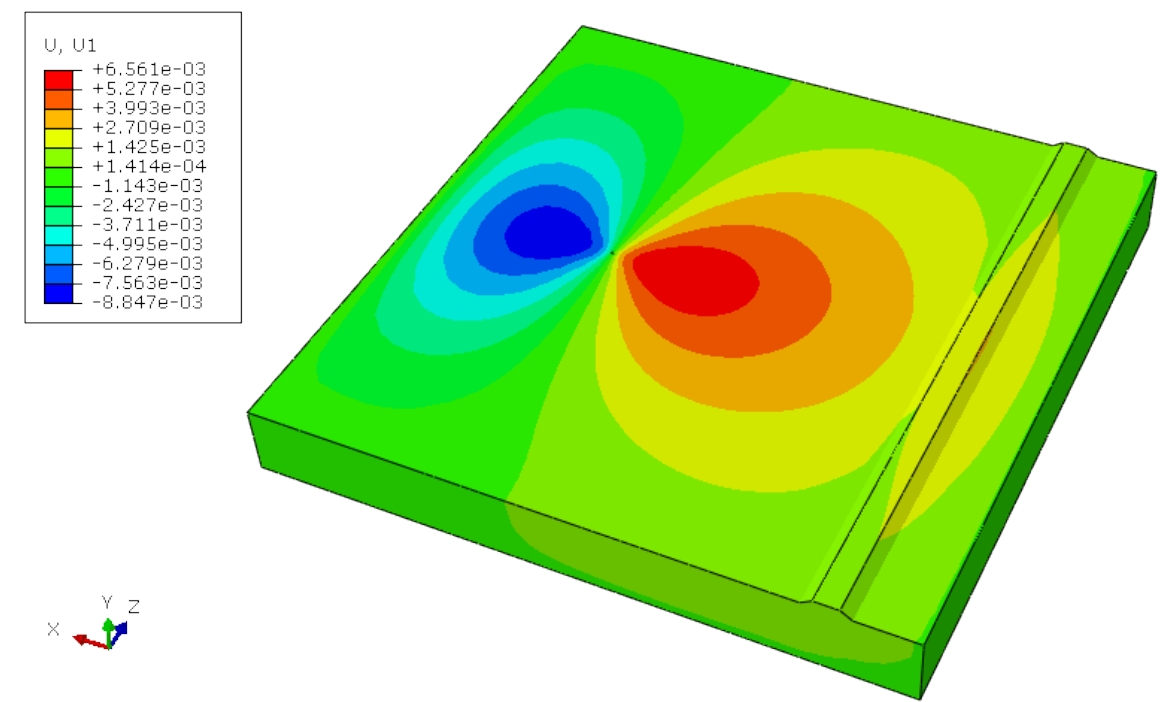

Fig. (6). Contours of lateral deformation.
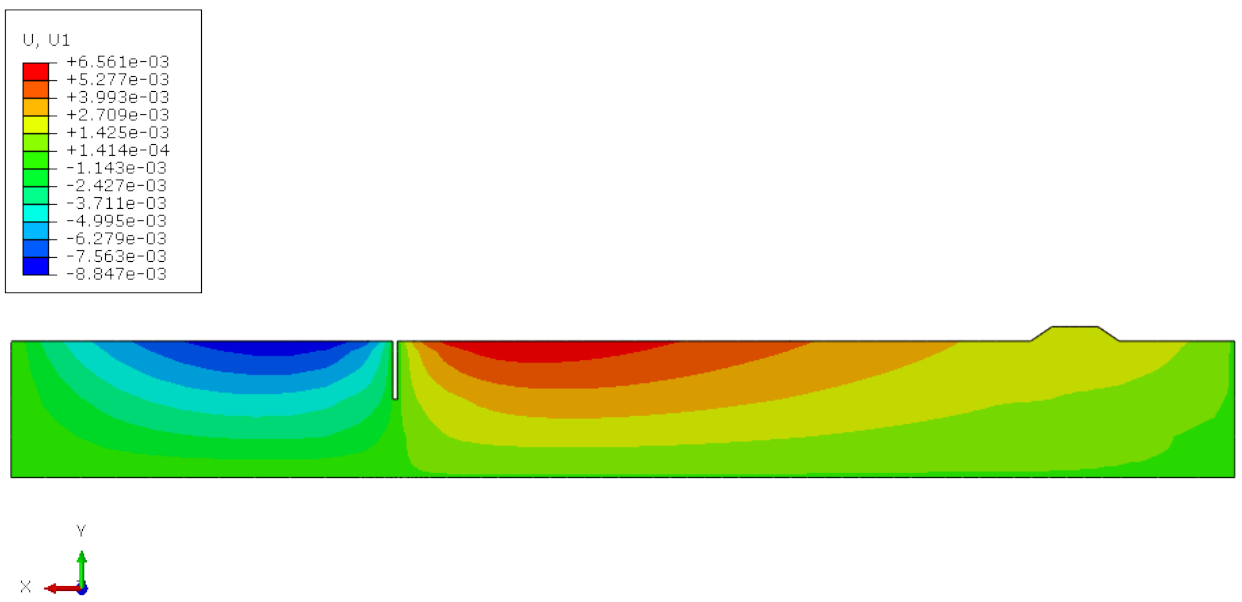

Fig. (7). Cross section of lateral deformation contours.

As can be seen from the figures above, subsidence of embankment along the longitudinal direction shows as a "concave" shape, lateral deformation along the longitudinal direction shows as a "convex" shape, and the maximum values both appear in the center of embankment surface, which is nearest to the well.
As can be seen from Table 2, when pumping rate is 250 $\mathrm{m}^{3} / \mathrm{d}$, subsidence value is $1.18 \mathrm{~mm}$, when pumping rate is $1500 \mathrm{~m}^{3} / \mathrm{d}$, subsidence value is $4.83 \mathrm{~mm}$, and the latter is 3 times larger than the former. When pumping rate is 250 $\mathrm{m}^{3} / \mathrm{d}$, lateral deformation value is $0.71 \mathrm{~mm}$, when pumping rate is $1500 \mathrm{~m}^{3} / \mathrm{d}$, lateral deformation value is $2.76 \mathrm{~mm}$, and 
the latter is 2.9 times larger than the former. Obviously, pumping rate is of great influence on the subsidence and lateral deformation of embankment. The maximum deformation value has a linear relationship with the pumping rate, and the larger the pumping rate, the greater the deformation. Therefore, pumping rate near high-speed railway should be strictly limited, because great pumping rate can induce large subsidence and lateral deformation value of the land and the embankment, which will directly affect the wheel-rail forces of upper track structure and safety of train operation.

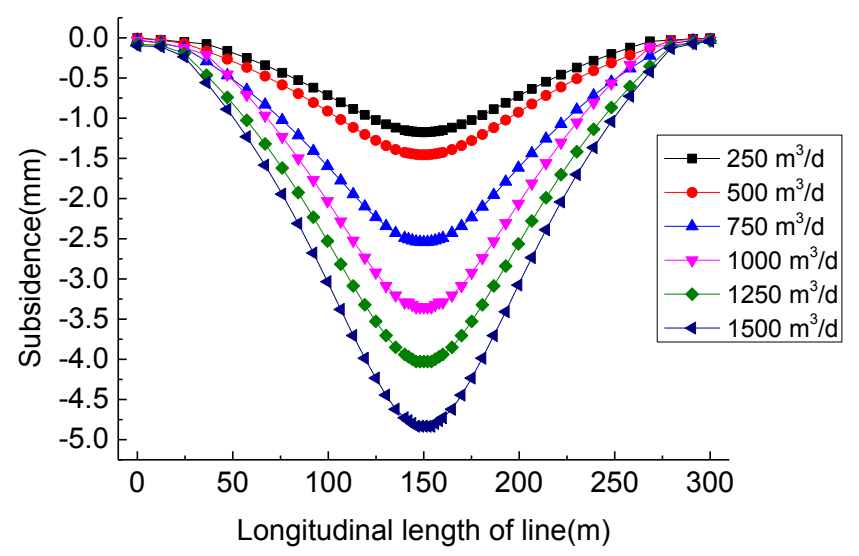

Fig. (8). Influence of pumping rateon subsidence of embankment.

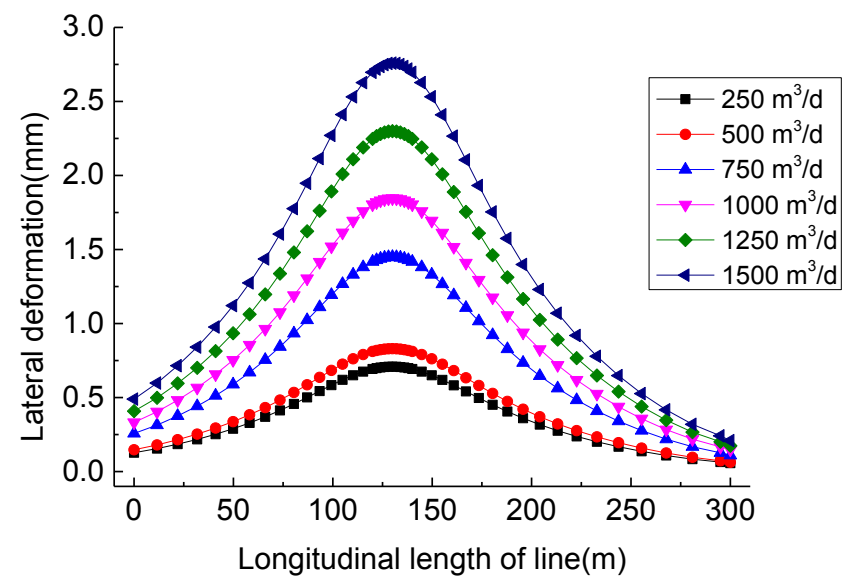

Fig. (9). Influence of pumping rateon lateral deformation of embankment.

Table 2. Maximum values of subsidence and lateral deformation.

\begin{tabular}{|c|c|c|}
\hline $\begin{array}{c}\text { Pumping Rate } \\
\left(\mathbf{m}^{\mathbf{3}} / \mathbf{d}\right)\end{array}$ & $\begin{array}{c}\text { Subsidence } \\
(\mathbf{m m})\end{array}$ & $\begin{array}{c}\text { Lateral Deformation } \\
(\mathbf{m m})\end{array}$ \\
\hline \hline 250 & 1.18 & 0.71 \\
\hline 500 & 1.46 & 0.83 \\
\hline 750 & 2.54 & 1.45 \\
\hline 1000 & 3.35 & 1.85 \\
\hline 1250 & 4.03 & 2.30 \\
\hline 1500 & 4.83 & 2.76 \\
\hline
\end{tabular}

\subsection{Influence of Different Pumping Distances on Embankment}

To study the influence of distance from pumping well to the center of embankment on embankment deformations, under the condition of pumping rate at $1000 \mathrm{~m}^{3} / \mathrm{d} \mathrm{m}$, the working conditions with five different pumping distances $50 \mathrm{~m}, 75 \mathrm{~m}, 100 \mathrm{~m}, 150 \mathrm{~m}, 200 \mathrm{~m}$ are analyzed. The center of embankment surface is selected as the object of study, and the results are shown in Figs. $(\mathbf{1 0}, \mathbf{1 1})$.

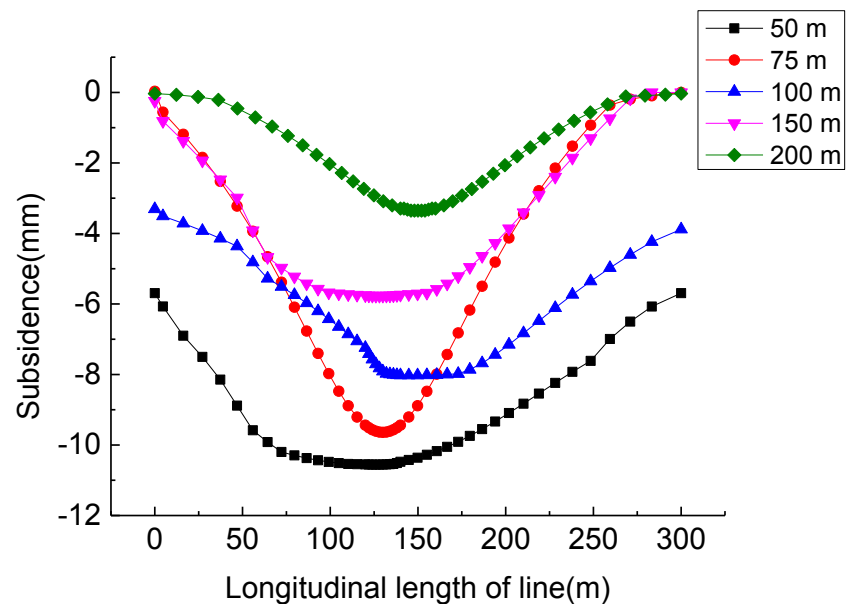

Fig. (10). Influence of pumping distance on subsidence of embankment.

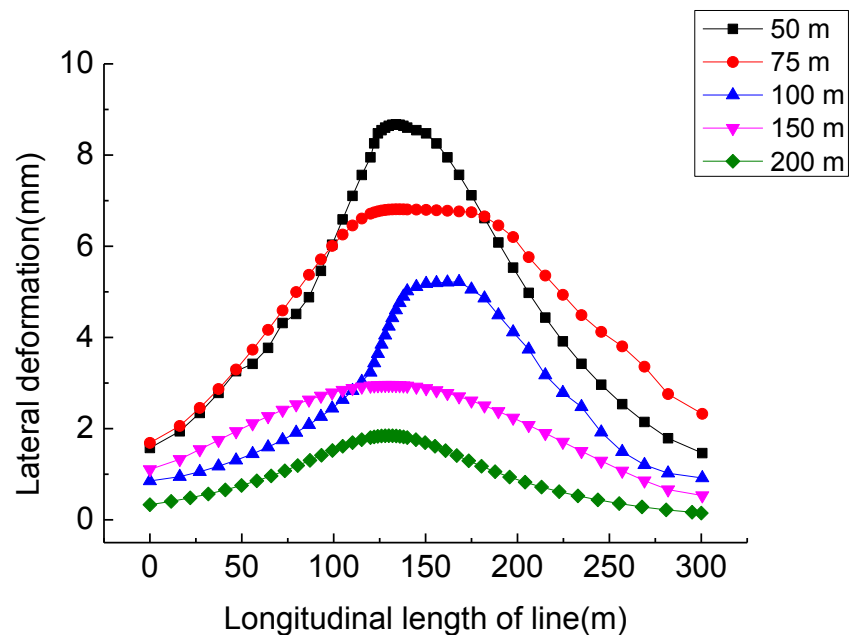

Fig. (11). Influence of pumping distance on lateral deformation of embankment.

As can be seen from the figures above, subsidence of embankment along the longitudinal direction shows as a "concave" shape, lateral deformation along the longitudinal direction shows as a "convex" shape, and the maximum values both appear in the center of embankment surface, which is nearest to the well, and the influencing law is similar to that of pumping rate on embankment deformations.

As can be seen from Table $\mathbf{3}$, when pumping distance is $50 \mathrm{~m}$, subsidence value is $10.55 \mathrm{~mm}$, when pumping distance is $200 \mathrm{~m}$, subsidence value is merely $3.35 \mathrm{~mm}$, and the latter is $68.2 \%$ smaller than the former. When pumping distance 
is $50 \mathrm{~m}$, lateral deformation value is $8.66 \mathrm{~mm}$, when pumping distance is $200 \mathrm{~m}$, lateral deformation value is merely $1.85 \mathrm{~mm}$, and the latter is $78.6 \%$ smaller than the former, which decreases exponentially. Obviously, pumping distance is also of great influence on the subsidence and lateral deformation of embankment. The influence of pumping on embankment decreases with the increasing distance of pumping well to embankment.

Table 3. Maximum values of subsidence and lateral deformation.

\begin{tabular}{|c|c|c|}
\hline $\begin{array}{c}\text { Pumping Distance } \\
(\mathbf{m})\end{array}$ & $\begin{array}{c}\text { Subsidence } \\
(\mathbf{m m})\end{array}$ & $\begin{array}{c}\text { Lateral Deformation } \\
(\mathbf{m m})\end{array}$ \\
\hline \hline 50 & 10.55 & 8.66 \\
\hline 75 & 9.63 & 6.81 \\
\hline 100 & 7.99 & 5.23 \\
\hline 150 & 5.76 & 2.95 \\
\hline 200 & 3.35 & 1.85 \\
\hline
\end{tabular}

\section{CONCLUSION AND SUGGESTIONS}

A 3-D fluid-solid coupling model is established for the analysis of groundwater exploitation near embankment using ABAQUS finite element program. The influence of pumping rate and pumping distance on embankment for high-speed railway are analyzed. Conclusions and suggestions are as follows:

The extraction of shallow groundwater will induce the drawdown of groundwater, as well as the decrease of pore pressure and increase of effective stress of soil, which will lead to deformations of soil, and land subsidence distribution is fundamentally in accordance with groundwater funnel area.

(2) Influence of pumping rate to deformations of embankment for high-speed railway is very prominent. The maximum deformation value has a linear relationship with the pumping rate, and the larger the pumping rate, the greater the deformation. Pumping rate near high-speed railway should be strictly limited, because great pumping rate can induce large subsidence and lateral deformation value of the land and the embankment, which will directly affect the wheel-rail forces of upper track structure and safety of train operation.

Pumping distance is of great influence on deformations of embankment. The influence of pumping on embankment decreases with the increasing distance of pumping well to embankment. Therefore, in order to control the influence of groundwater exploitation on embankment, it should be forbidden to add new pumping well near the railway and groundwater exploitation should be strictly limited within the influence scope.

\section{CONFLICT OF INTEREST}

The authors confirm that this article content has no conflict of interest.

\section{ACKNOWLEDGEMENTS}

This work was financially supported by Science and technology research and development program of China Railway Corporation (2013G004-A-2), Beijing Nova Program (Z12111000250000) and National Natural Science Foundation of China Financing Projects (U1234211).

\section{REFERENCES}

[1] G. H. Li, Z. L. Xu and S. L. Sun, "The influence of surface subsidence on construction of high-speed railway in North China plain and its countermeasures," Journal of Railway Engineering Society, vol. 24, pp. 7-12, 2007.

[2] Q. C. He, W. B. Liu and Z. M. Li, "Land subsidence survey and monitoring in the North China plain," Geological Journal of China Universities, vol. 12, pp. 195-209, 2006.

[3] G. H. Zhang, Y. H. Fei and Z. L. Nie, J. Shen, H. Li, and J. Wang, "Mechanism and trend of land subsidence in the east Haihe River plain," The Chinese Journal of Geological Hazard and Control, vol. 16, pp. 13-17, 2007.

[4] W. T. Zhao and L. Liang, "Mechanism of land subsidence and its prevention measures in Suzhou-Wuxi-Changzhou area," The Chinese Journal of Geological Hazard and Control, vol. 20, pp. 88-93, 2009.

[5] C. J. Wu, "The influence of regional subsidence in Suzhou-WuxiChangzhou and Shanghai areas on Beijing-Shanghai high-speed railway and its prevention countermeasures," Journal of Railway Engineering Society, no. 1, suppl 1, pp. 9-12, 2007.

[6] Z. X. Wei, H. M. Wang and J.Z. Wu, "Land subsidence and its influences on urban security of Shanghai," Shanghai Geology, vol. 1, pp. 34-39, 2009.

[7] Y. Zhang, Y. Q. Xue and Q. F. Li, "Current prominent subsidence layer and its deformation properties in Shanghai," Hydrogeology and Engineering Geology, vol. 30, pp.6-11, 2003.

[8] Code For Design Of High Speed Railway, Ministry of Railways of the People's Republic of China, 2009.

[9] K. Shen, Impacts and Solutions of the Regional Land Subsidence to the Embankment of Beijing-Shanghai High-Speed Railway, Southwest JiaoTong University: China, 2013.

[10] M. H. Marin, and T. J. Burbey, "The role of faulting on surface deformation patterns from pumping-induced groundwater flow," Hydrogeology Journal, vol, 17. pp. 1859-1875, 2009. 